\title{
ÇOĞUNLUK ALGILAMA MEKANİZMASININ İNHİBİSYONUNDA BİTKİSEL MATERYALLERİN KULLANIMI
}

\author{
Gülten Tiryaki Gündüz*, Ayça Korkmaz Vurmaz \\ Ege Üniversitesi, Mühendislik Fakültesi, Gıda Mühendisliği Bölümü, İzmir, Türkiye
}

Geliş / Received: 27.11.2020; Kabul / Accepted: 01.01.2021; Online bask1 / Published online: 18.01.2021

Gündüz, G.T., Vurmaz, A.K. (2021). Çoğunluk alg1lama mekanizmasının inhibisyonunda bitkisel materyallerin kullanımı. GIDA (2021) 46(2) 256-268 doi: 10.15237/gida.GD20134

Gündüz, G.T, Vurmaz, A.K. (2021). Use of plant-derived materials for the inbibition of qourum sensing mechanisms. GIDA (2021) 46(2) 256-268doi: 10.15237/gida.GD20134

\section{ÖZ}

Mikroorganizmaların hücre yoğunluğuna bağlı gen düzenleme sistemi çoğunluk algılama (Quorum Sensing) olarak adlandırılan mekanizma tarafindan kontrol edilmektedir. Çoğunluk algılama mekanizması (QS) ekzopolisakkarit üretimi, biyofilm oluşumu ve virülans faktörü gibi popülasyon fizyolojisini düzenleyen fenotipleri kontrol eden mekanizmadır. Son yıllarda gıdaların bozulması ve gıda güvenliği alanlarında QS mekanizmasının rolü üzerine araştırmalar artmıştur. Çoğunluk algılama mekanizmasının inaktivasyonu stratejisine, çoğunluk algılama mekanizmasının inhibisyonu (Quorum Quenching-QQ) adı verilmektedir. Yapılan çalışmalar, QQ mekanizmasının mikrobiyel gelişimin inhibisyonunda önemli bir rol oynadığını ve kimyasal koruyucu yerine gida güvenliğini arttrmak için alternatif bir strateji olabileceğini göstermiştir. Bitkisel materyaller, mikroorganizmalann gelişimini inhibe edici doğal antimikrobiyel bileşikler içerdikleri için potansiyel QS inhibitörü kaynaklarıdır. Bu derlemede, bitkisel materyaller kullanılarak çoğunluk alg1lama mekanizmasının inhibisyonu (QQ) stratejilerine odaklanılmışır.

Anahtar kelimeler: Çoğunluk algılama mekanizması, çoğunluk alg1lama mekanizmasının inhibisyonu, bitkisel materyal, antimikrobiyel.

\section{USE OF PLANT-DERIVED MATERIALS FOR THE INHIBITION OF QOURUM SENSING MECHANISMS}

\begin{abstract}
The gene regulation system of microorganisms through a cell density-dependent is controlled by a mechanism called Quorum Sensing. Quorum Sensing (QS) mechanism is a population physiology to control many characteristics regulated phenotypes like exopolysaccharide production, biofilm formation and virulence factor. In recent years, there is an increasing number of researches on the involvement of QS mechanism in the spoilage of food products and food safety. The strategy of inactivation of the QS is called Quorum Quenching (QQ). Studies have shown that QQ mechanism which plays a significant role in the inhibition of microbial growth might provide an alternative strategy to chemical preservatives for improving food safety. Plant-derived materials are promising potential sources of QS inhibitor as they can contain natural antimicrobial substances that inhibit the growth of microorganisms. In this review, the inhibition strategies of quorum sensing mechanism (QQ) by using plant-derived materials are focussed on.
\end{abstract}

Keywords: Quorum Sensing, Quorum Quenching, plant-drived material, antimicrobial.

${ }^{*}$ Yazışmalardan sorumlu yazar/ Corresponding author

$\triangle$ gulten.tiryaki.gunduz@ege.edu.tr, gtgunduz@gmail.com, ○(+90) 2323113003 县 (+90) 2323114831

Gülten Tiryaki Gündüz; ORCID no: 0000-0002-5878-7411

Ayça Korkmaz Vurmaz; ORCID no: 0000-0003-2084-5337 


\section{GİRIŞ}

İletişim yeteneğinin çok hücreli organizmalara özgü bir özellik olduğu düşünülmesine rağmen son yillarda yapılan araştırmalar ile mikroorganizmaların popülasyon yoğunluğuna dayalı bir iletissim mekanizmasına sahip olduğu belirlenmiştir (Stephens ve Bentley, 2020). Bu iletişim mekanizması sayesinde, mikroorganizmalar çevresinde bulunan mikrobiyel popülasyon hakkında bilgi edinmekte ve bu bilgileri gen ekspresyonunu düzenlemek için kullanmaktadır (Abisado vd., 2018; Quecan vd., 2019). Yapılan çalışmalar ile bu mekanizmanin, genlerin ifadesine dayanan hücreler arası iletişim sistemleri aracıllğıyla çeşitli hücre fenotiplerinin düzenlenmesinde rol oynadığ1 belirlenmiştir (Whiteley vd., 2017). Mikrobiyel popülasyon yoğunluğuna duyarlı gen düzenleme sistemini tanımlamak için "quorum sensing" terimi kullanılmaktadır. Hücreler arası iletişim mekanizması, salt çoğunluk anlamına gelen "quorum" ve algilama anlamina gelen "sensing" kelimelerden oluşan "quorum sensing" mekanizmasi olarak adlandirılmaktadir (Tommonaro vd., 2019).

QS mekanizmasında mikroorganizmalar belirli hücresel fonksiyonları harekete geçiren oto uyarıcı (autoinducer-AI) olarak adlandırllan hücreler arası iletişimde sinyal molekülleri olarak kullanılan moleküller üretmektedir (Erhabor vd., 2019). Üretilen sinyal molekülleri belirli mikroorganizmalara özgü hücresel fonksiyonları harekete geçiren moleküllerdir (Almasoud vd., 2016). Yapılan çalışmalarda hücresel fonksiyonları harekete geçiren sinyal molekülü konsantrasyonunun, sicaklık, $\mathrm{pH}$, gelişme ortam1, inokulum miktarı ve mikrobiyel gelişim evresine bağlı olarak değiştĭgi belirlenmiştir (Skandamis ve Nychas, 2012). QS mekanizmasinda rol oynayan sinyal molekülleri mikroorganizmalara özgü farklılıklar göstermektedir. Genel olarak sinyal molekülü ve algilama şekline göre QS mekanizmasi molekülleri AI-1, AI-2 ve AIP olarak üç kategoride toplanabilmektedir. Bakteriler temel olarak farklı yollarla QS sinyal iletimine aracilik eden AI-1 ve AI-2 sinyal molekülleri üretebilmektedir (Liu vd., 2018a).
Gram negatif bakteriler tarafindan türler arası iletişim için kullanılan sinyal molekülleri $\mathrm{N}$-açil homoserin laktondur. Küçük bir molekül olan Naçil homoserin lakton (AHL) sinyal molekülleri, hidrofilik bir homoserin lakton halkasi ve hidrofobik bir açil yan zincirden oluşmaktadır (O'Connor vd., 2015). LuxI/LuxR sisteminde AHL sentaz (LuxI) ve AHL reseptörü (LuxR transkripsiyon regülatörü) ile sentezlenen sinyal molekülü olarak $\mathrm{N}$-açil homoserin laktonlar (AHL) kullanılmaktadır. AHL sinyal molekülleri LuxI tarafindan sentezlenmekte olup, oldukça küçük bir molekül olduğu için oluşan derişim gradyanı farkından dolayı hücre dışına serbestçe difüze olabilmektedir (Passos da Silva vd., 2017). LuxS tarafindan kodlanmış olan Oto uyarıcı 2 (AI-2) sinyal molekülü, S-adenosilmetiyoninden (SAM) AI-2 sentaz enzimi tarafindan katalize edilen kararsız sinyal molekülü öncüsü 4,5dihidroksi-2,3-pentanedion (DPD) oluşumu süreciyle sentezlenmektedir (Gori vd., 2011). AI2 sinyal molekülünün hem Gram negatif hem de Gram pozitif bakteriler tarafindan kullanılan, türler arası iletişimin aksine farklı bakteri türlerinin birbirleriyle iletişim kurabileceği olası bir yolu temsil ettiği öne sürülmektedir. Yapilan çalışmalar, bu sinyal molekülünün çok sayıda bakteri türü tarafindan sentezlenmesinde aynı genin sorumlu olduğunu göstermektedir (Galloway vd., 2011).

Gram pozitif bakteriler tarafindan QS mekanizmasının kontrolü için için kullanılan sinyal molekülleri oligopeptitlerdir. QS mekanizması modifiye sinyal molekülleri oligopeptitlerden (AIP) ve histidin kinazdan (HK) oluşmaktadır (Singh vd., 2018). AIP, hücre membranından serbestçe dağılamayan modifiye bir oligopeptittir. AIP aracilı QS için sinyalizasyon işlemi, histidin kinaz tarafindan iletilmektedir (Gopu vd., 2018). Üretilen sinyal molekülleri açil homoserin lakton gibi serbestçe hücre membranından geçemeyecek büyüklükte olmasından dolayı sinyal molekülleri hücre dışına farklı taşıma mekanizmaları ile taşınmaktadır. Sinyal molekülü miktarı eşik değere ulaştı̆ı zaman, hücre yüzeyindeki alıcı bölgeler ile sinyal molekülü etkileşimi sonucunda fosforilasyon meydana gelmektedir. Birçok patojen bakteri 
toksin üretirken QS mekanizmasını kullanmaktadır. Bakteri popülasyonu ancak yeterli konsantrasyona ulaşınca patojen mikroorganizma konağa saldırmakta ve enfeksiyon süreci başlatılmaktadır (Papenfort ve Bassler, 2016). Mikrobiyel popülasyonun eşik değere ulaşması durumunda QS mekanizmasi ile ilgili davranışların sergilenmesi mümkün olmaktadır (Rutherfor ve Bassler, 2012). QS mekanizmas1 aracilığılla salt çoğunluk miktarını algılayarak belirli gen ekspresyonlarını gerçekleştirmeleri mikroorganizmalara önemli avantajlar sağlamaktadır. QS mekanizması patojenite, biyofilm oluşumu ve biyolüminesans gibi birçok fizyolojik özelliği kontrol etmekte ve popülasyonun fizyolojisinde birçok düzenlemenin yapılabilmesini sağlamaktadır (Yuan vd., 2018).

Düzenleyici sistem olarak çoğunluk algılama mekanizması (Quorum Sensing) yaklaşımı

Mikrobiyel gıda bozulmaları, gıda endüstrisi için önemli ekonomik kayılara neden olmakta ve özellikle aynı anda toksik metabolitler de üretildiğinde bir halk sağllğ1 sorunu oluşturabilmektedir. Gıda sektöründe, bozulmaya ve/veya gıda kaynaklı hastalıklara neden olan mikroorganizmalar ile ilgili sorunlar ile siklıkla karşılaşılmaktadır. $\mathrm{Bu}$ nedenle, gidalarda mikrobiyel gelişimi önlemek için farklı yöntemler kullanılmaktadır. Uygulanan yöntemler arasında en çok tercih edilenler; düşük sıcaklık, düşük su aktivitesi, 1sıl işlem, modifiye atmosfer, radyasyon uygulamalar1 ve antimikrobiyel madde kullanımıdır (Khan vd., 2019). Son yıllarda, gidaların bozulmasını önlemek veya geciktirmek için mevcut uygulamalara alternatif olabilecek potansiyel araçlardan biri olduğu düşünülen hücre-hücre iletişim mekanizmasının kontrolü araştırilmaktadır. QS, gidaların bozulmasında ve g1da güvenliği alanlarında anahtar düzenleyici sistem olarak kabul edilmektedir. Mikrobiyel kaynaklı gida bozulmaları en yaygin bozulma tipi olarak karşımıza çıkmaktadır (Galie vd., 2018). Gıdalarda bulunan proteinlerin, pektinlerin vb. parçalanması ile gıdaların bozulmasına neden olan birçok mikrobiyel hücre dışı enzim üretimi QS mekanizması tarafindan düzenlenmektedir (Liu vd., 2007). QS mekanizmasi tarafindan düzenlenen proteolitik, lipolitik ve pektinolitik enzim aktivitesine bağlı olarak gerçekleşen gida bozulmaları Çizelge 1'de verilmiştir.

Çizelge 1. Farklı gıdalarda QS mekanizmasıyla kontrol edilen bozulmalar ile ilgili davranışlar

\begin{tabular}{llll}
\hline Gida & Mikroorganizma & $\begin{array}{l}\text { QS mekanizmasina } \\
\text { bağli davranı̧ }\end{array}$ & Kaynaklar \\
\hline Et & Hafnia alvei & Proteolitik bozulma & Bruhn vd., 2004 \\
Balık & Aeromonas salmonicida & Proteolitik bozulma & Liu vd., 2018b \\
Balık & Pseudomonas fluorescens & Proteolitik bozulma & Li vd., 2018 \\
Karides & Shewanella baltica & Proteolitik bozulma & Zhu vd., 2018 \\
Süt & Acinetobacter spp. & Proteolitik bozulma & Yuan vd., 2020 \\
& Pseudomonas a a otoformans & Lipolitik bozulma & \\
Maş fasulyesi filizi & Serrita liquefaciens & Pektinolitik bozulma & Rasch vd., 2005 \\
\hline
\end{tabular}

QS mekanizmas1, mikroorganizmaların gen ekspresyonlarını sinyal molekülleri aracıllğıyla popülasyon yoğunluğuna göre düzenleyen bir iletişim mekanizmasıdır (Jung vd., 2016). Yapılan çalışmalarda, farklı gıda ürünlerinde farklı sinyal molekülleri tespit edilmiş olup, farklı mikroorganizma türlerinin QS mekanizması ile ilgili davranışları Çizelge 2'de özetlenmiştir.
Mikroorganizmalar kimyasal madde, ultraviyole 1ş1k, $\mathrm{pH}$, sıcaklık, enzim ve antibiyotikler gibi olumsuz koşullardan korunmak için biyofilm oluşturmaktadır. Biyofilm oluşumundaki en önemli etkenlerden birinin QS mekanizmas1 olduğu bilinmektedir (Khan vd., 2019). P. aeruginosa, L. monocytogenes, B. subtilis gibi pek çok mikroorganizmada QS mekanizmasının biyofilm oluşumunu regüle ettiği belirtilmiştir (Çizelge 2). 
Çizelge 2. Farklı mikroorganizmaların QS mekanizması ile ilgili davranışlanı

\begin{tabular}{llll}
\hline Mikroorganizma & Sinyal molekülü & QS mekanizması ile ilgili davranışlar & Kaynaklar \\
\hline Pseudomonas aeruginosa & AHL & Biyofilm & Luciardi vd., 2019 \\
Aeromonas sobria & AHL & Virulans & Li vd., 2016 \\
P. fluorescens & AHL & Biyofilm, Virulans & Li vd., 2018 \\
Listeria monocytogenes & AI-2 & Biyofilm & Melian vd., 2019 \\
Bacillus subtilis & AI-2 & Biyofilm & Duanis-Assaf vd., 2016 \\
Staphylococcus aureus & AIP & Virulans & Peng vd., 2019 \\
\hline
\end{tabular}

QS mekanizmasının farklı kullanım alanları hakkında pek çok araştırma yapılmaktadır. Belirli QS sinyal moleküllerini algilayan biyosensörler, g1da örneğinde bulunan çeşitli patojenlerin belirlenmesine olanak sağlamaktadır. Biyosensörlerin kullanımının geleneksel yöntemlere göre birçok avantajı bulunmaktadır. QS sinyal moleküllerini algilayan biyosensörlerin, bu sinyalleri üreten bakteri türlerinin ucuz, hılı ve güvenilir tespiti için kullanılabilecek önemli bir araçtır (Miller ve Gilmore, 2020).

Bazı laktik asit bakterileri tarafindan üretilen QS sinyal molekülleri olan oligopeptitlerin (AIP), gida endüstrisinde koruyucu olarak kullanilma potansiyeli olan antimikrobiyel özelliklere sahip olduğu belirtilmektedir (Kalia, 2018). QS mekanizmasının fermente gida üretiminde görev alan mikroorganizmalar arası iletişimde rol oynadığ1 ileri sürülmektedir. Gıda endüstrisinde çeşitli fermente gıdaların üretiminde yer alan mikroorganizmalar aras1 QS mekanizmasinin belirlenmesi ile üretilen farklı fermente gidalann kalitesinin arttırılabileceği düşünülmektedir (Park vd., 2016; Johansen ve Jespersen, 2017).

\section{Çoğunluk algılama mekanizmasının inhibisyonu (Quorum Quenching)}

Çoğunluk algilama mekanizmasının bloke edilerek inaktivasyonu stratejisine "çoğunluk algılama mekanizmasinin inhibisyonu (Quorum Quenching, QQ)" adı verilmektedir. Çoğunluk algilama mekanizmasinin inhibisyonu mikroorganizmalar arası iletişimi keserek, ilgili gen ekspresyonlarının engellenmesidir. QS inhibisyonu ile, mikroorganizmaları temel yaşam faaliyetlerine saldırarak öldürmeye çalışmak yerine, stres koşulları oluşturmadan ve biyofilm formlarına dönüşmelerine izin vermeden hücreler arası iletişimleri kesilerek mikroorganizmalann virulans1 engellenebilmektedir (Dong vd., 2007). $\mathrm{Bu}$ nedenle çoğunluk algilama mekanizmasının inhibisyonu umut verici bir mikrobiyel kontrol stratejisi olarak kabul edilmektedir (Zhang vd., 2019).

QS mekanizmasının bloke edilmesi ile bakterilerin iletişimi kesilebilmekte ve biyofilm oluşturmaları engellenerek savunmasiz kalmaları sağlanabilmektedir (Christiaen vd., 2014). QS mekanizmasını engelleyen maddelerin gidalarda mikrobiyel gelişimi kontrol etmek amacıyla kullanılabilme potansiyeli bulunmaktadır (Machado vd., 2020). Geleneksel yöntemlerden farklı olarak, hücreler arası iletişimin engellenmesi ile mikrorganizmaların çoğalmasının önleneceği, bozulmaların azaltılarak gıdaların raf ömrünün uzatılabileceği ve gida kaynaklı hastalıkların azaltılabileceği düşünülmektedir (Ta ve Arnason, 2016; Borges vd., 2017; Machado vd., 2020). G1da bozulmalarının ve gida kaynaklı mikrobiyel hastalıkların önüne geçilmesi açısından da mikroorganizmaların QS inhibisyon mekanizmalarının anlaşılması son derece önemlidir. QS inhibisyon mekanizmaları ile ilgili yaklaşımlar; sinyal molekülü sentezinin inhibisyonu, sinyal molekülünün inhibisyonu ve sinyal molekülü alımının ve transdüksiyonun önlenmesi şeklinde temel olarak üç mekanizma ile açıklanmaktadır (Chbib, 2020).

Genel olarak çoğunluk algılama mekanizması inhibisyonu aktivitesine sahip maddeler doğal ve sentetik inhibitörler olarak iki kategoriye ayrilabilmektedir. QS mekanizmasının bloke edilmesi için kullanılan moleküllerin kimyasal sentezi ya da doğal ürünün yapisina uygun moleküler modifikasyonu ile sinyal moleküllerinin baz1 yapisal analoglan sentetik olarak tasarlanabilmektedir (Majik vd., 2020). Doğal 
sinyal moleküllerinin kimyasal yapısına dayalı olarak sentezlenen rekabetçi sinyal molekülü inhibitörleri çoğunluk algılama mekanizmasının inhibisyonu için kullanılabilmektedir. Sentetik sinyal molekülleri, bakteriyel enfeksiyon ve biyofilm oluşumunu kontrol etmek amaciyla uygulanabilmektedir (Zhang vd., 2019).

Tibbi ve aromatik bir bitki olan tarçının içeriğinde önemli miktarda sinnamaldehit bulunmaktadır. Tarçının başlıca biyoaktif bileşiği olan sinnamaldehit antioksidan, antikanserojen ve antibakteriyel etkilere sahip doğal bir bileşiktir (Chenia, 2015). Brackman vd. (2008) tarafindan yapılan çalışmada sinnamaldehidin, QS yanıt düzenleyicisi LuxR'nin DNA bağlanma kabiliyetini azaltarak QS ile düzenlenen virülans faktörünü inhibe ettiği belirlenmiştir. Sinnamaldehit analoglarının yapı-aktivite ilişkisi hakkında gerçekleştirilen çalışmada da farklı sinnamaldehit analoglarının etkinliği belirlenmiş olup, en aktif sinnamaldehit analoglarının düşük sitotoksisite sergilemesinin yanı sıra Vibrio spp.'nin biyofilm oluşumunu, pigment üretimini ve proteaz üretimini de etkilediği tespit edilmiştir (Brackman vd., 2011).

Laktonaz, açilaz, oksidoredüktaz gibi QS inhibe edici enzimler ve bu enzimlere sahip mikroorganizmalar sinyal molekülünü hedef transkripsiyonel regülatöre bağlanamaz hale getirerek sinyal molekülünün etkinliğini azaltmakta ve böylelikle ilgili gen ekspresyonunu bloke edebilmektedir (Chen vd., 2013). Açilaz enzimi AHL sinyal moleküllerinin tam ve geri dönüşümsüz bozunmasını sağlayan enzimlerdir. Laktonaz ve paraoksonaz enzimleri AHL lakton sinyallerinde bulunan homoserin lakton halkasinı hidrolize etmektedir. 4- Nitro piridin- N- oksit, pbenzokinon, indol, 3-nitrobenzen, 6-Gingerol ve Amorfrutin B gibi sentetik QS inhibitörlerin kullanımı ile QS inhibisyonun sağlandığı belirtilmiştir (Kiran vd., 2017). Delisea pulchra deniz yosunu tarafından üretilen halojenlenmiş furanonlar, sinyal molekülünün alınmasını önleyerek QS inhibisyonunu sağlamaktadır. Halojenlenmiş furanonların, sinyal molekülü ile varsayılan bağlanma noktası arasındaki etkileşimi engellediği tespit edilmiştir (Zhang vd., 2019).
Ancak, QS inhibisyonunda kullanımı araştırılan halojenlenmiş furanonların; tup, tarım ve gida endüstrisinde kullanılmak için kararsız ve toksik olduğu belirlenmiştir (Skandamis ve Nychas, 2012). QS sinyal mekanizmasının engellenmesinde kullanılabilecek kimyasal maddelerin toksik yan etkileri olmayan, yüksek derecede özgüllük sergileyen ve kimyasal olarak stabil moleküller olması gerekmektedir (Rasmussen ve Givskov, 2006). Bu nedenle, sentetik inhibitörlere alternatif olabilecek bitkisel kaynaklı materyallerin QS inhibitörü olarak kullanımı araştırılmaktadır.

Bitkisel materyeller ile çoğunluk algılama mekanizmasının inhibisyonu

Bitkisel materyaller antimikrobiyel aktiviteden sorumlu olan fenolik asitler, saponinler, flavonlar, kumarin türevleri, terpenoidler ve alkaloidler gibi fitokimyasallar içermektedir. Bu nedenle bitkisel materyallerin QS inhibisyon ajanları için iyi bir kaynak olduğu belirtilmektedir (Majik vd., 2020). QS inhibisyonu için kimyasal inhibitörler yerine bitkisel materyallerin kullanımı ile ilgili birçok çalışma bulunmaktadır (Var ve Çelik, 2019). Kimyasal inhibitörlere alternatif olabilecek bitkisel ekstraktlar QS inhibisyonunu; sinyal moleküllerinin sentezlenmesini azaltarak, reseptör proteinlerinin aktivitesini azaltarak, sinyal moleküllerini inhibe ederek, sinyal moleküllerini reseptör proteinlerinden ayırarak ve sinyal moleküllerinin yerine geçerek gerçekleştirmektedir (Truchado vd., 2015). QS inhibisyonu için bitkisel kaynakların kullanımı hakkında yapılan çalışmalar Çizelge 3'te özetlenmiştir.

Yapılan birçok araştırmada, gıda ektraktlarının antimikrobiyel ve anti-QS aktivitesi değerlendirilmiş olup, aynı zamanda bu aktiviteden sorumlu biyoaktif bileşikler de tespit edilmiştir. Gıdanın içeriğinde bulunan fitokimyasalların hem kimyasal yapilarının sinyal moleküllerine benzerliklerinden hem de sinyal reseptörlerini bozma yeteneklerinden dolayı QS inhibitörü olarak görev aldıkları belirlenmiştir. Truchado vd. (2012) tarafindan yapilan bir çalışmada nar ekstraktı ile AHL sinyal molekülü üretimindeki azalmanın kısmen AHL sinyal 
moleküllerin degradasyonu ve transformasyonundan kaynaklandiğı belirtilmiştir. Sinnamaldehit, ellagik asit ve resveratrol gibi birçok farklı fitokimyasal bileşiğin Yersinia enterocolitica ve E. carotovora gibi bakterilerin AHL sistemini inhibe etme potansiyeline sahip olduğu tespit edilmiştir. Zhou vd. (2018) tarafindan yapılan bir çalışmada $P$. aeruginosa PAO1'e karşı resveratrolün etkili bir QS inhibitörü olabileceği ortaya konulmuştur. qRT-PCR analizi ile $P$. aeruginosa PAO1 biyofilmlerinde ilgili gen ekspresyonunun resveratrol tarafindan engellendiği belirlenmiştir.

Çizelge 3. QS mekanizmasının inhibisyonunda bitkisel materyallerin kullanımı

\begin{tabular}{|c|c|c|c|}
\hline $\begin{array}{l}\text { Bitkisel materyal } \\
\text { (Ekstrakt/fitokimyasal) }\end{array}$ & $\begin{array}{l}\text { Test } \\
\text { mikroorganizmalar1 }\end{array}$ & Etki mekanizmasi & Kaynaklar \\
\hline $\begin{array}{lr}\text { Mango } & \text { yaprağ1 } \\
\text { (Mangifera } & \text { indica) } \\
\text { ekstrakt } & \end{array}$ & $\begin{array}{l}\text { Chromobacterium } \\
\text { violaceum } \\
\text { Aeromonas bydrophila } \\
\text { P. aeruginosa }\end{array}$ & $\begin{array}{l}\text { QS inhibisyonuna bağlı olarak } \\
\text { ekzopolisakkarit, proteaz ve kitinaz üretim } \\
\text { aktivitesinin azalması, } \\
\text { AHL sinyal molekülüne bağlı pigment } \\
\text { üretiminin azalması, biyofilm oluşumunun } \\
\text { engellenmesi }\end{array}$ & $\begin{array}{l}\text { Husain vd., } \\
2017\end{array}$ \\
\hline \multirow[t]{2}{*}{$\begin{array}{l}\text { Defne yaprağ1 (Laurus } \\
\text { nobilis) ekstrakt1 }\end{array}$} & $\begin{array}{l}\text { S. aureus } \\
P . \\
\text { Escherichiararinosa } \\
\text { Salmonella enterica }\end{array}$ & $\begin{array}{l}\text { Gıda kaynaklı } r \text { patojen } \\
\text { mikroorganizmalara karşı } \\
\text { aktivite }\end{array}$ & $\begin{array}{l}\text { Molina } \\
2020\end{array}$ \\
\hline & $\begin{array}{l}\text { C. violaceum } \\
\text { P. aeruginosa }\end{array}$ & $\begin{array}{l}\text { Anti-QS aktivite, biyofilm oluşumunun } \\
\text { inhibisyonu }\end{array}$ & \\
\hline \multirow[t]{2}{*}{$\begin{array}{l}\text { Yabani mantar } \\
\text { (Amanita rubescens, } \\
\text { Russula delica, } \\
\text { Lactarius } \\
\text { ekstraktlar1 sp.) }\end{array}$} & $\begin{array}{l}\text { S. aureus } \\
\text { E. coli } \\
\text { P. aeruginosa } \\
\text { L. monocytogenes } \\
\text { Enterococcus faecalis } \\
\text { Klebsiella pneumoniae } \\
\text { Proteus mirabilis } \\
\text { Candida albicans }\end{array}$ & Mikrobiyel gelişimin inhibisyonu & \multirow[t]{2}{*}{$\begin{array}{l}\text { Tabbouche } \\
\text { vd., } 2017\end{array}$} \\
\hline & C. violaceum & $\begin{array}{l}\text { Amanita rubescens ve Lactarius sp. mantar } \\
\text { ekstraktlarının } \quad(625 \quad \mu \mathrm{g} / \mathrm{ml}) \text { QS } \\
\text { inhibisyonu }\end{array}$ & \\
\hline Yeşil çay polifenolleri & $\begin{array}{l}\text { Vibrio harveyi } \\
\text { C. violaceum }\end{array}$ & $\begin{array}{l}\text { Soğukta depolanan baliklarda bozulma } \\
\text { etmeni olan Shewanella baltica tarafindan } \\
\text { üretilen AI-2 sinyal molekülünün } \\
\text { degredasyonu, biyofilm } \\
\text { ekzopolisakkarit üretiminin inhibisyonu }\end{array}$ & Zhu vd., 2015 \\
\hline $\begin{array}{l}\text { Misır anason (Carum } \\
\text { copticum) tohumu } \\
\text { esansiyel yağı ve } \\
\text { ekstraktı }\end{array}$ & $\begin{array}{l}\text { S. aureus } \\
\text { E. coli } \\
\text { B. cereus } \\
\text { L. monocytogenes } \\
\text { E. faecalis } \\
\text { K. pneumonia } \\
\text { Serratia marcescens } \\
\text { Salmonella spp. }\end{array}$ & $\begin{array}{l}\text { Esansiyel yağ ve metanol ekstraktı ile test } \\
\text { mikroorganizmalarına karşı mikrobiyel } \\
\text { inhibisyon }\end{array}$ & $\begin{array}{l}\text { Snoussi } \\
2018\end{array}$ \\
\hline
\end{tabular}


Pseudomonas spp.

Vibrio spp.

Candida spp.

Saccharomyces cerevisiae

C. violaceum

C. copticum esansiyel yağ1 $(0.23 \mathrm{mg} / \mathrm{ml})$ ile viyolasin pigmenti üretiminin $\% 50$ inhibisyonu

Kestane (Castanea sativa Mill.) çiçeği ekstraktları

Mandalina (Citrus reticulate) esansiyel yağ1

Tarhun (Artemisia dracunculus L.) esansiyel yağ1

Trans-sinnamaldehit

Salisilik asit

Sinnamaldehit
S. aureus

E. coli

B. subtilis

E. faecalis

K. pneumonia

Salmonella spp.

Candida spp.

C. violaceum

$P$. aeruginosa

P. aeruginosa

Pseudomonas spp.

$P$. aeruginosa

\section{P. fluorescens}

Test mikroorganizmalarına karşı güçlü antimikrobiyel aktivite

C. sativa metanol ekstraktı ile viyolasin üretimi, kayma hareketi ve biyofilm oluşumunun inhibisyonu

Biyofilm oluşumunun inhibisyonu, AHL Luciardi vd., sinyal molekülünün üretimini ve elastaz 2016 enzim aktivitesinin azalması

Tarhun esansiyel yağı ile QS sinyal Sobieszczańska molekülü sentezinin ve proteolitik vd., 2020 aktivitenin azalması

QS düzenleyici ve virülans genlerin Ahmed vd., ekspresyonunun inhibisyonu 2019

P. fluorescens tarafindan üretilen AHL sinyal molekülü üretiminde bir değişiklik olmazken, sinnamaldehit ile balık fileto örneklerinde proteolitik bozulmanın inhibisyonu

QS mekanizmas1 ile ilgili gen ekspresyonunun azalması, biyofilm oluşumu, fenazin üretimi ve kayma hareketinin inhibisyonu
Li vd., 2018

GutiérrezBarranquero vd., 2015
C. violaceum Agrobacterium tumefaciens
Alilizotiyosiyanat, benzilizotiyosiyanat, 2feniletilizotiyosiyanat, gallik asit, ferulik asit, kafeik asit, phlorizin, (-) epikateşin fitokimyasallarının QQ mekanizmasinın test edildiği bir araşturmada, alilizotiyosiyanat, benzilizotiyosiyanat ve 2 -feniletilizotiyosiyanatn AHL sinyal molekülü aktivitesi üzerinde etki ederek QS inhibe edici etki gösterdiği tespit edilmiştir (Borges vd., 2014). Ancak yapılan in vitro antimikrobiyel ve sitotoksik analizler, terapötik antimikrobiyel olarak ferulik asit, phlorizin ve epikateşinin potansiyel olarak kullanılabileceğini göstermiştir.

Luciardi vd. (2019) tarafindan yapılan bir çalışmada, greyfurt esansiyel yağının $1 \mathrm{mg} / \mathrm{mL}$ konsantrasyonda $P$. aeruginosa'in biyofilm oluşturmasını engellediği tespit edilmiştir. Çalışmada greyfurt esansiyel yağının ana bileşeni olan D-limonenin etkisi de araşturlmış olup, D- 
limonenin biyofilm oluşumunun inhibisyonda esansiyel yağlardan daha az etkili olduğu ve esansiyel yağın içerisinde bulunan minör bileşenlerin QS mekanizmasının inhibisyonunda sinerjistik etkisi olabileceği belirtilmiştir.

Çoğunluk algılama mekanizması ile ilişkili $P$. fluorescens KM121 türü tarafindan gerçekleştirilen biyofilm oluşumunun inhibisyonunda kekik (Thymus vulgaris L.) esansiyel yağ1 ve başlica biyoaktif bileşikleri olan karvakrol ve timolün etkisinin araştırıldığı bir çalışmada, test edilen materyallerin AHL sinyal molekülü üretimini inhibe ettiği tespit edilmiştir. Ayrıca, test materyallerinin $P$. fluorescens suşu tarafindan gerçekleştirilen biyofilm oluşumunu etkili bir şekilde inhibe ettiği belirlenmiştir (Myszka vd., 2016). Kekik esansiyel yağının ve kekik esansiyel yağı ilave edilmiş pektin filmlerin C. violaceum için QS inhibitör aktivitesinin araştırlldığ bir çalışmada, kekik esansiyel yağ1 ilaveli pektin filmlerin tüm konsantrasyonlarda $(15.7,25.9$ ve $36.1 \mathrm{mg} / \mathrm{mL}$ ) C. violaceum tarafindan viyolasin üretiminin inhibisyonu olarak ifade edilen önemli bir QS inhibisyon aktivitesi gösterdiği belirlenmiştir (Alveres vd., 2014). Mohan vd. (2019) tarafindan yapılan bir çalışmada antimikrobiyel ve antioksidan etkilerini arttırmak için film matriksine ilave edilen partikül boyutu azaltılmış karanfil (Syyyggium aromaticum) ve tarçın (Cinnamomum cassia) içeren yenilebilir ambalaj filmlerin $P$. aeruginosa tarafindan üretilen biyofilmi etkili bir şekilde inhibe ettiği ve tavuk örneklerinin raf ömrünü uzatmak için önemli katk1 sağladığ tespit edilmiştir. Mikrobiyel gelişimin inhibisyonu için QQ mekanizmasının, raf ömrü kısa olan gıda ürünlerinde sürdürülebilir koruma yöntemlerinin geliştirilmesinde faydalı olabileceği belirtilmiştir. Farklı esansiyel yağlar ve bileşenlerinin, QS inhibisyon ve anti-biyofilm aktivitesine dayalı olarak uygulanmasının gidaların raf ömrünü ve güvenliğini artırmak için yeni bir strateji olarak kullanılabileceği rapor edilmiştir (Bai ve Vittal, 2014; Zhang vd., 2018).

Turşudan izole edilmiş olan Lactobacillus plantarum izolatnnin, Aeromonas sobria tarafindan virülans faktörlerin üretimi ve biyofilm oluşturma mekanizmasının düzenlenmesi için üretilen, AHL sinyal moleküllerinde yaklaşık \%100 bozunma sağladığı belirlenmiştir. Elde edilen sonuçlar laktik asit bakterilerinin gıda güvenliğini arttırmak için umut verici bir QS inhibitörü ve anti-biyofilm ajanı olarak kullanım potansiyeli olabileceğini göstermiştir (Lv vd., 2021).

\section{SONUÇ}

Günümüzde önemli bir sorun haline gelen antimikrobiyel maddelere dirençli mikroorganizmalar sebebiyle, QS inhibisyonu araştırmaları önem kazanmaktadır. Gıdalarda bozulmay1 önlemek veya geciktirmek için koruyucu olarak kullanılabilecek farklı inhibitörler bulunmaktadır. Gıdanın raf ömrünü öngörebilmek için tüm iç ve dış faktörleri dikkate alarak bir gida matrisinde hücreler arası iletişim modellerinin araştırılması gerekmektedir. QS mekanizmasının inhibisyonu için QS mekanizmasını engelleyen maddelerin gidalarda mikrobiyel gelişmeyi kontrol etmek amaciyla kullanım potansiyeli bulunmaktadır. Bu sayede hem gida bozulmalarinın hem de patojenlerin neden olduğu gida kaynaklı mikrobiyel hastalıkların kontrol altna alınabileceği düşünülmektedir. Gıda güvenliğini arttırmak ve gidaların raf ömrünü uzatmak için QS inhibitörlerinin gida koruyucusu olarak kullanılabilme potansiyeli ile ilgili daha çok çalışmaya ihtiyaç duyulmaktadır.

\section{ÇIKAR ÇATIŞMASI BEYANI}

Yazarlar, bu makale ile ilgili olarak başka kişiler ve/veya kurumlar arasında çıkar çatışması olmadığını beyan etmektedir.

\section{YAZAR KATKILARI}

Tüm yazarlar makalenin yazilmasinda ve yayınlanmasında katkı sağlamışlardır. Makalenin hazırlanmasında başka kişi ve/veya kurumların katk1s1 yoktur.

\section{KAYNAKLAR}

Abisado, R.G., Benomar, S., Klaus, J.R., Dandekar, A.A., Chandler, J.R. (2018). Bacterial Quorum Sensing and microbial community interactions. MBio, 9(3), e02331-17, doi: 10.1128/mBio.02331-17. 
Ahmed, S.A., Rudden, M., Smyth, T.J., Dooley, J. S., Marchant, R., Banat, I.M. (2019). Natural quorum sensing inhibitors effectively downregulate gene expression of Pseudomonas aeruginosa virulence factors. Appl Microbiol Biotechnol, 103(8): $\quad 3521-3535, \quad$ doi: 10.1007/s00253-019-09618-0.

Almasoud, A., Hettiarachchy, N., Rayaprolu, S., Babu, D., Kwon, Y.M., Mauromoustakos, A. (2016). Inhibitory effects of lactic and malic organic acids on autoinducer type 2 (AI-2) quorum sensing of Escherichia coli O157: $\mathrm{H} 7$ and Salmonella Typhimurium. LWT - Food Sci Technol, 66: 560-564, doi: 10.1016/j.lwt.2015.11.013.

Alvarez, M.V., Ortega-Ramirez, L.A., GutierrezPacheco, M.M., Bernal-Mercado, A.T., Rodriguez-Garcia, I., Gonzalez-Aguilar, G.A., Ponce, A., Moreira, M. R., Roura, S. I., AyalaZavala, J.F. (2014). Oregano essential oil-pectin edible films as anti-quorum sensing and food antimicrobial agents. Front Microbiol, 5, 699, doi: 10.3389/fmicb.2014.00699.

Borges, A., Serra, S., Cristina Abreu, A., Saavedra, M.J., Salgado, A., Simões, M. (2014). Evaluation of the effects of selected phytochemicals on quorum sensing inhibition and in vitro cytotoxicity. Biofouling, 30(2): 183-195, doi: 10.1080/08927014.2013.852542.

Borges, A., Sousa, P., Gaspar, A., Vilar, S., Borges, F., Simões, M. (2017). Furvina inhibits the 3-oxoC12-HSL-based quorum sensing system of Pseudomonas aeruginosa and QS-dependent phenotypes. Biofouling, 33(2): 156-168, doi: 10.1080/08927014.2017.1280732.

Brackman, G., Celen, S., Hillaert, U., Van Calenbergh, S., Cos, P., Maes, L., Nelis, H.J., Coenye, T. (2011). Structure-activity relationship of cinnamaldehyde analogs as inhibitors of AI-2 based quorum sensing and their effect on virulence of Vibrio spp. PLoS One, 6(1), e16084, doi: 10.1371/journal.pone.0016084.

Brackman, G., Defoirdt, T., Miyamoto, C., Bossier, P., Van Calenbergh, S., Nelis, H., Coenye, T. (2008). Cinnamaldehyde and cinnamaldehyde derivatives reduce virulence in Vibrio spp. by decreasing the DNA-binding activity of the quorum sensing response regulator LuxR. $B M C$ Microbiol, 8(1), 149, doi: 10.1186/1471-2180-8149.

Bruhn, J.B., Christensen, A.B., Flodgaard, L.R., Nielsen, K.F., Larsen, T.O., Givskov, M., Gram, L. (2004). Presence of acylated homoserine lactones (AHLs) and AHL-producing bacteria in meat and potential role of AHL in spoilage of meat. Appl Environ Microbiol, 70(7): 4293-4302, doi: 10.1128/AEM.70.7.4293-4302.2004.

Chbib, C. (2020). Impact of the structure-activity relationship of AHL analogues on quorum sensing in Gram- negative bacteria. Bioorg Med Chem, 28(3): 115282, doi: 10.1016/j.bmc.2019.115282.

Chen, F., Gao, Y., Chen, X., Yu, Z., Li, X. (2013). Quorum quenching enzymes and their application in degrading signal molecules to block Quorum Sensing-dependent infection. Int J Mol Sci, 14(9): $\quad 17477-17500, \quad$ doi: 10.3390/ijms140917477.

Chenia, H.Y. (2015). Antimicrobial activity of cinnamaldehyde, vanillin and Kigelia Africana fruit extracts against fish-associated Chryseobacterium and Myroides spp. isolates. Afr J Tradit Complement Altern Med,12(3): 55-67, doi: 10.4314/ajtcam.v12i3.7.

Christiaen, S.E., Matthijs, N., Zhang, X.H., Nelis, H.J., Bossier, P., Coenye, T. (2014). Bacteria that inhibit quorum sensing decrease biofilm formation and virulence in Pseudomonas aeruginosa PAO1. Pathog Dis, 70(3): 271-279, doi: 10.1111/2049-632X.12124.

Dong, Y.H., Wang, L.H., Zhang, L.H. (2007). Quorum-quenching microbial infections: mechanisms and implications. Phil Trans R Soc B, 362(1483): 1201-1211, doi: 10.1098/rstb.2007.2045.

Duanis-Assaf, D., Steinberg, D., Chai, Y., Shemesh, M. (2016). The LuxS based quorum sensing governs lactose induced biofilm formation by Bacillus subtilis. Front Microbiol, 6, 1517, doi: 10.3389/fmicb.2015.01517. 
Ekşi, S., Esertaş, Ü.Z.Ü., Kilic, A.O., Ejder, N., Uzunok, B. (2020). Determination of the antimicrobial and antibiofilm effects and 'Quorum Sensing' inhibition potentials of Castanea sativa Mill. extracts. Not Bot Horti Agrobo, 48(1): 66-78, doi: 10.15835/nbha48111736.

Erhabor, C.R., Erhabor, J.O., McGaw, L.J. (2019). The potential of South African medicinal plants against microbial biofilm and quorum sensing of foodborne pathogens: A review. $S$ Afr J Bot, 126: 214-231, doi: 10.1016/j.sajb.2019.07.024.

Galie, S., García-Gutiérrez, C., Miguélez, E.M., Villar, C.J., Lombó, F. (2018). Biofilms in the food industry: health aspects and control methods. Front Microbiol, 9, 898, doi: 10.3389/fmicb.2018.00898.

Galloway, W.R., Hodgkinson, J.T., Bowden, S.D., Welch, M., Spring, D.R. (2011). Quorum sensing in Gram-negative bacteria: small-molecule modulation of AHL and AI-2 quorum sensing pathways. Chem Rev,111(1): 28-67, doi: 10.1021/cr100109t.

Gopu, V., Chandran, S., Shetty, P.H. (2018). Significance and application of Quorum Sensing in Food Microbiology. In: Quorum Sensing and its Biotechnological Applications, Kalia, V.C. (ed.), Springer, Singapore, pp. 193-219.

Gori, K., Moslehi-Jenabian, S., Purrotti, M., Jespersen, L. (2011). Autoinducer-2 activity produced by bacteria found in smear of surface ripened cheeses. Int Dairy J, 21(1): 48-53, doi: 10.1016/j.idairyj.2010.06.009.

Gutiérrez-Barranquero, J.A., Reen, F.J., McCarthy, R.R., O'Gara, F. (2015). Deciphering the role of coumarin as a novel quorum sensing inhibitor suppressing virulence phenotypes in bacterial pathogens. Appl Microbiol Biotechnol, 99(7): 3303-3316, doi: 10.1007/s00253015-6436-1.

Husain, F.M., Ahmad, I., Al-thubiani Abdullah S., Abulreesh, H.H., AlHazza, I.M., Aqil, F. (2017). Leaf extracts of Mangifera indica L. inhibit Quorum Sensing - Regulated Production of virulence factors and biofilm in test bacteria. Front Microbiol, 8: 1-12, doi: 10.3389/fmicb.2017.00727.

Johansen, P., Jespersen, L. (2017). Impact of quorum sensing on the quality of fermented foods. Curr Opin Food Sci,13: 16-25, doi: 10.1016/j.cofs.2017.01.001.

Jung, S.A., Hawver, L.A., Ng, W.L. (2016). Parallel quorum sensing signaling pathways in Vibrio cholerae. Curr Genet, 62(2): 255-260, doi: 10.1007/s00294-015-0532-8.

Kalia, V.C. (ed.). (2018). Biotechnological applications of Quorum Sensing inbibitors. Springer, Singapore, $473 \mathrm{p}$.

Khan, D.M., Manzoor, M.A., Rao, I.V., Moosabba, M.S. (2019). Evaluation of biofilm formation, cell surface hydrophobicity and gelatinase activity in Acinetobacter baumannii strains isolated from patients of diabetic and nondiabetic foot ulcer infections. Biocatal Agric Biotechnol, 18, 101007, doi: 10.1016/j.bcab.2019.01.045.

Kiran, G.S., Hassan, S., Sajayan, A., Selvin, J. (2017). Quorum quenching compounds from natural sources. In: Bioresources and Bioprocess in Biotechnology, Sugathan, S. (chief ed.), Springer, Singapore, pp. 351-364.

Li, T., Cui, F., Bai, F., Zhao, G., Li, J. (2016). Involvement of acylated homoserine lactones (AHLs) of Aeromonas sobria in spoilage of refrigerated turbot (Scophthalmus maximus L.). Sensors, 16(7), 1083, doi: 10.3390/s16071083.

Li, T., Wang, D., Liu, N., Ma, Y., Ding, T., Mei, Y., Li, J. (2018). Inhibition of quorum sensingcontrolled virulence factors and biofilm formation in Pseudomonas fluorescens by cinnamaldehyde. Int J Food Microbiol, 269: 98-106, doi: 10.1016/j.ijfoodmicro.2018.01.023.

Liu, J., Fu, K., Wu, C., Qin, K., Li, F., Zhou, L. (2018a). "In-Group" communication in marine Vibrio: A review of N-Acyl homoserine lactonesdriven Quorum Sensing. Front Cell Infect Microbiol, 8, 139, doi: 10.3389/fcimb.2018.00139.

Liu, L., Yan, Y., Feng, L., Zhu, J. (2018b). Quorum sensing asaI mutants affect spoilage phenotypes, motility, and biofilm formation in a 
marine fish isolate of Aeromonas salmonicida. Food Microbiol, 76: 40-51, doi: 10.1016/j.fm.2018.04.009.

Liu, M., Wang, H., Griffiths, M.W. (2007). Regulation of alkaline metallo-protease promoter by $\mathrm{N}$-acyl homoserine lactone quorum sensing in Pseudomonas fluorescens. J Appl Microbiol,103(6): 2174-2184, doi: 10.1111/j.13652672.2007.03488.x.

Luciardi, M.C., Blázquez, M.A., Alberto, M.R., Cartagena, E., Arena, M.E. (2019). Grapefruit essential oils inhibit quorum sensing of Pseudomonas aeruginosa. Food Sci Technol Int, 26(3): 231-241, doi: 10.1177/1082013219883465.

Luciardi, M.C., Blázquez, M.A., Cartagena, E., Bardón, A., Arena, M.E. (2016). Mandarin essential oils inhibit quorum sensing and virulence factors of Pseudomonas aeruginosa. LWT - Food Sci Technol, 68: 373-380, doi: 10.1016/j.lwt.2015.12.056.

Lv, X., Cui, T., Du, H., Sun, M., Bai, F., Li, J., Zhang, D. (2021). Lactobacillus plantarum CY 1-1: A novel quorum quenching bacteria and antibiofilm agent against Aeromonas sobria. LWT- Food Sci Technol, 137, 110439, doi: 10.1016/j.lwt.2020.110439.

Machado, I., Silva, L.R., Giaouris, E.D., Melo, L.F., Simões, M. (2020). Quorum sensing in food spoilage and natural-based strategies for its inhibition. Food Res Int, 127, 108754, doi: 10.1016/j.foodres.2019.108754.

Majik, M.S., Gawas, U.B., Mandrekar, V.K. (2020). Next generation quorum sensing inhibitors: Accounts on structure activity relationship studies and biological activities. Bioorg Med Chem, 28(21), 115728, doi: 10.1016/j.bmc.2020.115728.

Melian, C., Segli, F., Gonzalez, R., Vignolo, G., Castellano, P. (2019). Lactocin AL 705 as quorum sensing inhibitor to control Listeria monocytogenes biofilm formation. J Appl Microbiol, 127(3): 911920, doi: 10.1111/jam.14348.

Miller, C., Gilmore, J. (2020). Detection of Quorum-Sensing molecules for pathogenic molecules using cell-based and cell-free biosensors. Antibiotics, 9(5),

259,

doi: 10.3390/antibiotics9050259.

Mohan, C.C., Harini, K., Sudharsan, K., Krishnan, K.R., Sukumar, M. (2019). Quorum quenching effect and kinetics of active compound from $S$. aromaticum and C. cassia fused packaging films in shelf life of chicken meat. $L W T$ - Food $S_{c i}$ Technol, 105: 87-102, doi: 10.1016/j.lwt.2019.01.061.

Molina, R.D.I., Campos-Silva, R., Díaz, M.A., Macedo, A.J., Blázquez, M.A., Alberto, M.R., Arena, M.E. (2020). Laurel extracts inhibit Quorum sensing, virulence factors and biofilm of foodborne pathogens. LWT - Food Sci Technol, 134, 109899, doi: 10.1016/j.lwt.2020.109899.

Myszka, K., Schmidt, M.T., Majcher, M., Juzwa, W., Olkowicz, M., Czaczyk, K. (2016). Inhibition of quorum sensing-related biofilm of Pseudomonas fluorescens KM121 by Thymus vulgare essential oil and its major bioactive compounds. Int Biodeterior Biodegrad, 114: 252-259, doi: 10.1016/j.ibiod.2016.07.006.

O’Connor, G., Knecht, L.D., Salgado, N., Strobel, S., Pasini, P., Daunert, S. (2015). Whole-cell biosensors as tools for the detection of quorumsensing molecules: uses in diagnostics and the investigation of the quorum-sensing mechanism. In: Bioluminescence: Fundamentals and Applications in Biotechnology, Thouand, G. (chief ed.), Volume 3, Springer, Cham, pp. 181-200.

Papenfort, K., Bassler, B.L. (2016). Quorum sensing signal- response systems in Gramnegative bacteria, Nat Rev Microbiol, 14(9): 576588, doi: 10.1038/nrmicro.2016.89.

Park, H., Shin, H., Lee, K., Holzapfel, W. (2016). Autoinducer-2 properties of kimchi are associated with lactic acid bacteria involved in its fermentation. Int J Food Microbiol, 225: 38-42, doi: 10.1016/j.ijfoodmicro.2016.03.007.

Passos da Silva, D., Schofield, M., Parsek, M., Tseng, B. (2017). An update on the sociomicrobiology of quorum sensing in Gramnegative biofilm development. Pathogens, 6, 51, doi: 10.3390/pathogens6040051. 
Peng, P., Baldry, M., Gless, B.H., Bojer, M.S., Gonora, C.E., Baig, S., Andersen, P.S., Olsen, C.A., Ingmer, H. (2019). Effect of co-inhabiting coagulase negative staphylococci on $S$. aureus agr quorum sensing, host factor binding, and biofilm formation. Front Microbiol, 10, 2212, doi: 10.3389/fmicb.2019.02212.

Quecan, B.X.V., Rivera, M.L.C., Hassimotto, N.M.A., Almeida, F.A.D., Pinto, U.M. (2019). Effect of quercetin rich onion extracts on bacterial quorum sensing. Front Microbiol, 10, 867, doi: 10.3389/fmicb.2019.00867.

Rasch, M., Andersen, J.B., Nielsen, K.F., Flodgaard, L.R., Christensen, H., Givskov, M., Gram, L. (2005). Involvement of bacterial quorum-sensing signals in spoilage of bean sprouts. Appl Environ Microbiol, 71(6): 3321-3330, doi: 10.1128/AEM.71.6.3321-3330.2005.

Rasmussen, T.B., Givskov, M. (2006). Quorumsensing inhibitors as anti-pathogenic drugs. Int $J$ Med Microbiol, 296(2-3): 149-161, doi: 10.1016/j.jimm.2006.02.005.

Rutherford, S.T., Bassler, B.L. (2012). Bacterial quorum sensing: its role in virulence and possibilities for its control. Cold Spring Harb Perspect Med,2(11): a012427, doi: 10.1101/cshperspect.a012427.

Singh, A., Gaur, M., Misra, R. (2018). Understanding the connect of quorum sensing and CRISPR-Cas system: potential role in biotechnological applications. In: Quorum Sensing and its Biotechnological Applications, Sugathan S. (chief ed.), Springer, Singapore, pp. 231-247.

Skandamis, P.N., Nychas, G.J.E. (2012). Quorum sensing in the context of food microbiology. Appl Environ Microbiol, 78(16): 5473-5482, doi: 10.1128/AEM.00468-12.

Snoussi, M., Noumi, E., Punchappady-Devasya, R., Trabelsi, N., Kanekar, S., Nazzaro, F., Fratianni, F., Flamini, G., Feo, V. D., Al-Sieni, A. (2018). Antioxidant properties and anti-quorum sensing potential of Carum copticum essential oil and phenolics against Chromobacterium violaceum.J Food Sci Technol, 55(8): 2824-2832, doi: 10.1007/s13197-018-3219-6.
Sobieszczańska, N., Myszka, K., Szwengiel, A., Majcher, M., Grygier, A., Wolko, Ł. (2020). Tarragon essential oil as a source of bioactive compounds with anti-quorum sensing and antiproteolytic activity against Pseudomonas spp. isolated from fish-in vitro, in silico and in situ approaches. Int J Food Microbiol, 108732, doi: 10.1016/j.ijfoodmicro.2020.108732.

Stephens, K., Bentley, W.E. (2020). Synthetic biology for manipulating Quorum Sensing in microbial consortia. Trends Microbiol, 28(8): 633643, doi: 10.1016/j.tim.2020.03.009.

Ta, C., Arnason, J. (2016). Mini review of phytochemicals and plant taxa with activity as microbial biofilm and quorum sensing inhibitors. Molecules, 21(1), 29, doi: $10.3390 /$ molecules21010029.

Tabbouche, S.A., Gürgen, A., Yildiz, S., Kiliç, A.O., Sökmen, M. (2017). Antimicrobial and antiquorum sensing activity of some wild mushrooms collected from Turkey. J Sci Technol MSU, 5(2): 453-457, doi: 10.18586/msufbd.347692.

Tommonaro, G. (ed.) (2019). Quorum Sensing: Molecular mechanism and biotechnological application. Academic Press, Cambridge, United Kingdom, $309 \mathrm{p}$.

Truchado, P., Larrosa, M., Castro-Ibáñez, I., Allende, A. (2015). Plant food extracts and phytochemicals: their role as quorum sensing inhibitors. Trends Food Sci Technol, 43(2): 189-204, doi: 10.1016/j.tifs.2015.02.009.

Truchado, P., Tomás-Barberán, F.A., Larrosa, M., Allende, A. (2012). Food phytochemicals act as quorum sensing inhibitors reducing production and/or degrading autoinducers of Yersinia enterocolitica and Erwinia carotovora. Food Control, 24(1-2): 78-85, doi: 10.1016/j.foodcont.2011.09.006.

Var, I., Çelik, Ç. (2019). Mikroorganizmalarda çoğunluğu algilama ve çoğunluğu algilama mekanizmasının engellenmesi. GID A 44 (6): 943953, doi: 10.15237/gida.GD19016.

Whiteley, M., Diggle, S.P., Greenberg, E.P. (2017). Bacterial quorum sensing: The progress 
and promise of an emerging research area. Nature, 551(7680), 313, doi: 10.1038/nature24624.

Yuan, L., Sadiq, F. A., Liu, T., Li, Y., Gu, J., Yang, H., He, G. (2018). Spoilage potential of psychrotrophic bacteria isolated from raw milk and the thermo-stability of their enzymes. $J$ Zhejiang Univ Sci B, 19(8): 630-642, doi: 10.1631/jzus.B1700352.

Yuan, L., Wang, N., Sadiq, F.A., He, G. (2020). RNA sequencing reveals the involvement of quorum sensing in dairy spoilage caused by psychrotrophic bacteria. LWT - Food Sci Technol, 127, 1093842, doi: 10.1016/j.lwt.2020.109384.

Zhang, J., Feng, T., Wang, J., Wang, Y., Zhang, X.H. (2019). The mechanisms and applications of Quorum sensing (QS) and Quorum quenching (QQ). J Ocean Univ China, 18(6): 1427-1442, doi: 10.1007/s11802-019-4073-5.

Zhang, Y., Kong, J., Xie, Y., Guo, Y., Cheng, Y., Qian, H., Yao, W. (2018). Essential oil components inhibit biofilm formation in Erwinia carotovora and Pseudomonas fluorescens via anti- quorum sensing activity. LWT - Food Sci Technol, 92: 133-139, doi: 10.1016/j.lwt.2018.02.027.

Zhou, J.W., Chen, T.T., Tan, X.J., Sheng, J.Y., Jia, A.Q. (2018). Can the quorum sensing inhibitor resveratrol function as an aminoglycoside antibiotic accelerant against Pseudomonas aeruginosa? Int J Antimicrob Agents, 52(1): 35-41, doi: 10.1016/j.ijantimicag.2018.03.002.

Zhu, J., Huang, X., Zhang, F., Feng, L., Li, J. (2015). Inhibition of quorum sensing, biofilm, and spoilage potential in Shewanella baltica by green tea polyphenols. J Microbiol, 53(12): 829-836, doi: 10.1007/s12275-015-5123-3.

Zhu, S., Wu, H., Zhang, C., Jie, J., Liu, Z., Zeng, M., Wang, C. (2018). Spoilage of refrigerated Litopenaeus vannamei: eavesdropping on Acinetobacter acyl-homoserine lactones promotes the spoilage potential of Shewanella baltica.J Food Sci Technol, 55(5): 1903-1912, doi: 10.1007/s13197-018-3108-z. 